\title{
The relationship between time to surgical debridement and incidence of infection in grade III open fractures
}

\author{
Jagwant Singh $\cdot$ Rohit Rambani $\cdot$ Zaid Hashim • \\ Raghu Raman · Hemant Kumar Sharma
}

Received: 13 February 2011 / Accepted: 12 March 2012/Published online: 31 March 2012

(C) The Author(s) 2012. This article is published with open access at Springerlink.com

\begin{abstract}
Objective The purpose of this study was to determine the association between time to initial debridement and infection rate in high-energy (grade III) open fractures of tibia.

Methods All patients presenting with open fractures were included in the study. The inclusion criteria were Gustilo III A, B and C open fractures of tibia. Time of injury, time of arrival to the hospital, time of initial debridement and subsequent soft tissue procedures were recorded. The primary outcome measure was a diagnosis of infection or osteomyelitis at 1 year. Secondary outcome measure was fracture union at 1 year.

Results Sixty-seven (67) patients with grade III open fractures were included; the mean age was 32.4 years (54 males and 13 females). Eight patients (12\%) in this study went on to develop a deep infection, and there were 6 $(8.4 \%)$ non-unions. The infection rate for patients in the group who underwent debridement in less than $6 \mathrm{~h}$ and those greater than $6 \mathrm{~h}$ was 13.1 and $10.8 \%$, respectively. No statistically significant difference could be demonstrated between the two groups $(p=0.56)$. While there was no significant relationship between grade of fracture and infection rate $(p=0.07)$, the relationship between grade of fracture and non-union was significant $(p=0.02)$. Conclusion Our study shows that the risk of developing an infection was not increased if the primary surgical management was delayed more than $6 \mathrm{~h}$ after injury. Therefore, reasonable delays in surgical treatment for
\end{abstract}

J. Singh $(\bowtie)$ - R. Rambani · Z. Hashim · R. Raman .

H. K. Sharma

Trauma and Orthopaedics, Hospital Hull Royal Infirmary,

Anlaby Road, Hull HU3 2JZ, UK

e-mail: drjagwant@gmail.com patients with open fractures may be justified in order to provide an optimal operating environment.

Keywords Grade III open fractures · Debridement . Infection rate

\section{Introduction}

Open tibial fractures pose a major treatment challenge for surgeons. Infection and non-union are the main complications after open diaphyseal fractures of the tibial [1-7]. The reported rate of infection is between 5 and $50 \%$ and that of non-union between 7 and $60 \%$ [1-6, 8-10]. In fractures complicated by infection or non-union, there will invariably be secondary procedures $[3,5,6,8-10]$. A thorough debridement, washout and skeletal stabilization are the mainstays of initial treatment along with intravenous antibiotics. Recent studies have advocated the role of early wound coverage as a means to decrease wound infection $[3,4,11]$. The urgency for debridement has not been clearly defined with mostly surgeons advocating within the first $6 \mathrm{~h}$ [12-14].

The origin of the 6-h rule is unclear. Friedrich, in his experiments on guinea pigs in 1898, reported lower infection rates when debridement was performed within $6 \mathrm{~h}$ [15]. Robson later confirmed this on human wounds [16]. The practice of treating open fractures within $6 \mathrm{~h}$ can result in complex operations being performed out of normal working hours by relatively inexperienced surgeons, anaesthetists and theatre staff with potentially sub-optimal results $[12,13]$.

We conducted this study to evaluate the association between time to initial surgical debridement and rates of infection in open fractures of the tibia. 


\section{Materials and methods}

All patients presenting to our hospital with Grade III open fractures of the tibia between 1997 and 2008 were included in the study. Approval from the local audit, research and development department was obtained. Data were collected retrospectively. The inclusion criteria were patients with Gustilo III A, B and C open fractures of tibia. Patients were excluded if they had a spinal cord injury, the presence of infection prior to the injury or a coincident full thickness burn. Patients who presented later than $24 \mathrm{~h}$ after the injury, referrals from other hospitals and those who were followed up in centres other than the study centre were also excluded.

The patients had been reviewed by the orthopaedic team upon presentation at the accident and emergency department (A\&E). Management included assessment of wound, removal of large contaminants, a photograph of open wound, cover with occlusive dressings and an assessment of the distal neurovascular status. All patients with clean wounds received intravenous antibiotics of either $1.5 \mathrm{~g}$ cefuroxime (Cefuroxime Axetil) or $1.2 \mathrm{~g}$ of Co-amoxyclav. Intravenous analgesia (Morphine) and tetanus prophylaxis was given as per immunization status. The patients were prepared for surgery (debridement and stabilization) immediately after initial presentation. The limiting factors to immediate surgery were associated comorbidities in the patient, grade of surgeon attending and emergency theatre access.

At surgery, all patients underwent wound debridement and fracture stabilization. Fractures were classified using the Gustilo and Anderson classification system [10, 17]. Plastic surgeons were involved in the early assessment, and the timing of subsequent debridement, definitive fixation and soft tissue procedures were decided jointly.

Patients received intravenous antibiotics for $48 \mathrm{~h}$ or longer depending on wound contamination, extent of debridement, surgeon assessment and timing of wound closure. Demographic data including the time of injury, time of presentation to the hospital, time of initial debridement and subsequent soft tissue procedures were noted. Comorbidities including diabetes and smoking were also noted. The patients were divided into two groups; those who had debridement within $6 \mathrm{~h}$ of injury $(<6 \mathrm{~h})$ and those who waited for more than $6 \mathrm{~h}(>6 \mathrm{~h})$.

The primary outcome measure was a diagnosis of infection or osteomyelitis up to 1 year. The patients were followed up regularly up to clinical and radiological fracture union or until a definitive procedure for infection or non-union had been carried out with a minimum subsequent follow-up of at least 1 year. Superficial infection that was adequately managed with a course of antibiotics was not included in our analysis. Pin tract infection (associated with external fixator use) not requiring surgery was also excluded.

The hypothesis was time to initial debridement does not influence the rate of infection in grade III open tibial fractures. Any evidence of wound infection led to culture swabs being taken and patients treated with a prolonged duration of intravenous antibiotics and, if needed, surgical intervention. Advice from a microbiologist was sought early. Patients who had wound infections confirmed by culture results were treated with prolonged antibiotics.

\section{Results}

Sixty-nine patients with grade III open fractures satisfied the inclusion criterion, out of which 67 were included in the study. One patient was transferred to another hospital for further treatment and was therefore excluded. Another died from an unrelated illness prior to fracture union.

The mean age was 32.4 years (7-89); we had 54 male and 13 female patients. Road traffic accident (RTA) was the most common mechanism of injury $(56.5 \%)$. Figure 1 shows the distribution of mechanism of injury. There were 26 grade III A fractures (39\%), 39 grade III B fractures (58\%) and 2 grade III C (3\%) as shown in Fig. 2. The majority of the patients in our study had fractures of the distal third of the tibia (Figs. 3, 4).

The time from injury to surgery ranged from $2 \mathrm{~h} 35 \mathrm{~min}$ to $12 \mathrm{~h}$ with an average time of $5 \mathrm{~h} 40 \mathrm{~min}$. Sixty-nine per cent of patients had their wound debridement within $6 \mathrm{~h}$ of presentation to the hospital. However, this reduced to $55 \%$ when time from injury to debridement was taken into consideration. The major reason for the delay was lack of prompt access to theatre.

The infection rate for patients who underwent debridement in less than $6 \mathrm{~h}$ was $13.1 \%$. Two patients, who had debridement within 6 hours, developed pin tract infection (away from original fracture site), were treated by oral

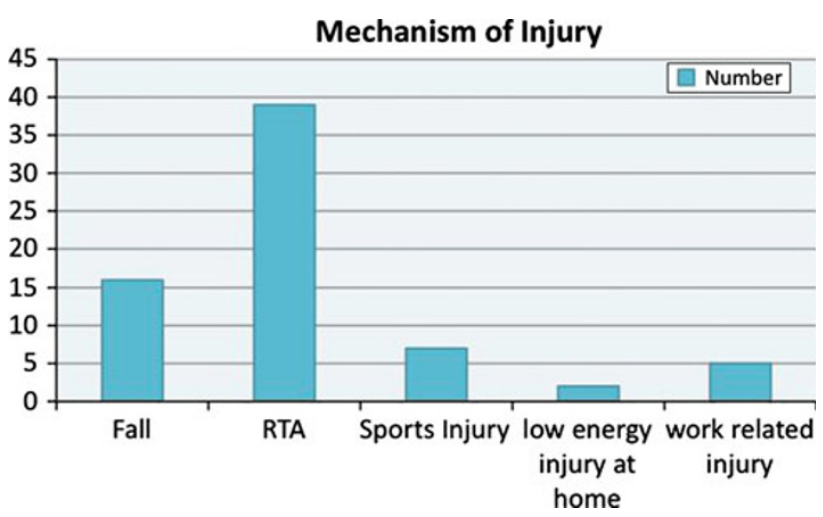

Fig. 1 Mechanism of injury 


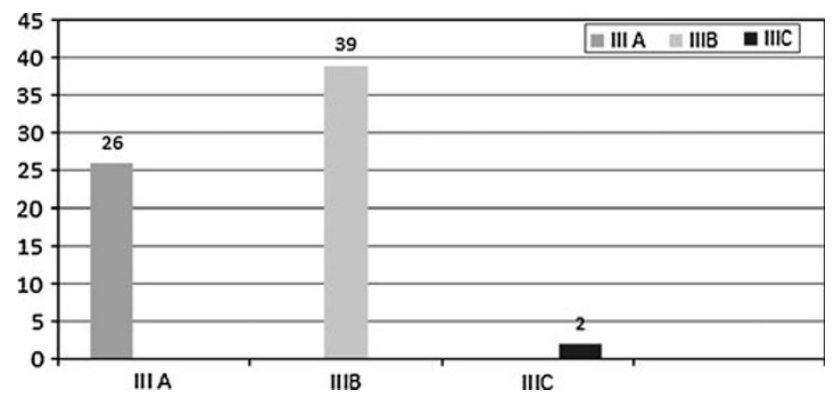

Fig. 2 Grades of fracture (Gustillo and Anderson classification)

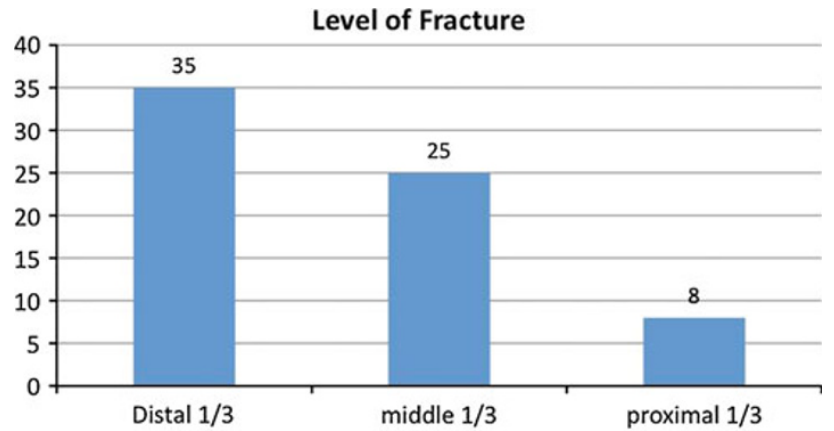

Fig. 3 Level of fracture

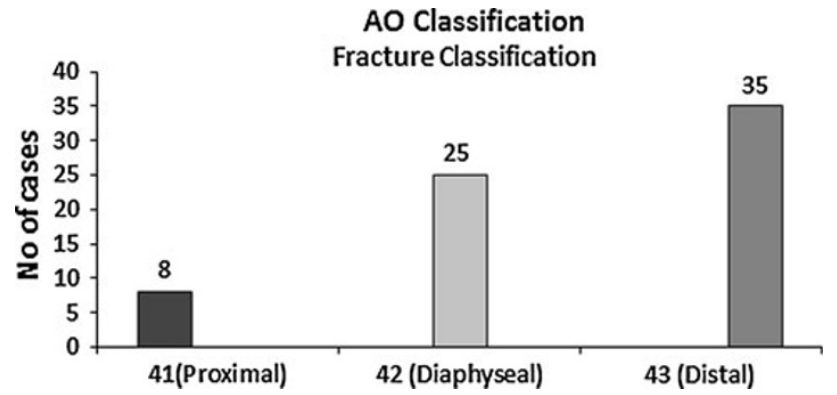

Fig. 4 AO classification

antibiotics and needed no further intervention. If these two cases of pin tract infection were included, the infection rate in this $<6 \mathrm{~h}$ group is $18.4 \%$ (Table 1 ). In contrast, the infection rate in those who underwent debridement after $6 \mathrm{~h}$ group was $10.8 \%$. The results were analysed using Fisher's exact test and no statistically significant difference could be demonstrated between the two groups $(p=0.560)$.

Eight patients (12\%) developed a deep infection. There were $6(8.4 \%)$ non-unions. Of the eight with deep infection, five were from the $<6 \mathrm{~h}$ group and three from the $>6 \mathrm{~h}$ group.

Grade III B fractures had the highest rate of infection and non-union at twenty and thirteen per cent, respectively. When the grade of fracture was paired with infection, the $p$ value was not statistically significant $(p=0.07$, paired sample $t$ test). When grade of fracture was paired to
Table 1 Infection and non-union in the two groups

\begin{tabular}{lllll}
\hline $\begin{array}{l}\text { Time delay to } \\
\text { debridement }\end{array}$ & No & Infection & Non-union & $\begin{array}{l}\text { United without } \\
\text { infection }\end{array}$ \\
\hline$<6 \mathrm{~h}$ & 38 & $7(18.4 \%)^{\mathrm{a}}$ & 5 & 33 \\
$>6 \mathrm{~h}$ & 29 & $3(10.8 \%)$ & 1 & 26 \\
\hline
\end{tabular}

${ }^{a}$ This includes two cases of pin tract infection, which were managed successfully with oral antibiotics, and no further surgical intervention was required

Table 2 Association between various grades of fracture and infection and non-union rate ( $p$ value $<0.05$ is significant)

\begin{tabular}{lllll}
\hline Fracture & $\begin{array}{l}\text { III A } \\
(N=26)\end{array}$ & $\begin{array}{l}\text { III B } \\
(N=39)\end{array}$ & $\begin{array}{l}\text { III C } \\
(N=2)\end{array}$ & $p$ value \\
\hline Infection & 0 & 8 & 0 & 0.07 \\
Non-union & 1 & 5 & 0 & 0.02 \\
Delayed union & 2 & 1 & 0 & \\
Pin tract infection/ & 0 & 2 & 0 & \\
$\quad$ superficial infection & & & & \\
\hline
\end{tabular}

non-union, the $p$ value was statistically significant $(p=0.02$, Table 2).

There was no increase in infection rate in those treated after $6 \mathrm{~h}$ compared with those treated within $6 \mathrm{~h}$.

\section{Discussion}

The key elements in managing open fractures of tibia include prompt and appropriate antibiotics, debridement, skeletal stabilization and early soft tissue cover [18]. Debridement is an important surgical step in the management of open tibial fractures. Much evidence is provided in the literature to support early debridement. The experimental studies by Friedrich [15] and Robson [19] showed the infection threshold of $10^{5}$ organisms per gram of tissue was reached in at an average of $5.17 \mathrm{~h}$ [16]. Clinical studies by Kreder and Armstrong, Kindsfather and Jonassen have supported the importance of the 6 -h rule $[14,16$, 20]. However, it should be noted that studies by Friedrich and Robson were carried out in pre-antibiotic era [19].

There are studies $[12,13,21-25]$ that challenge the 6-h rule for open tibial fractures; these have found no difference between early and delayed treatment groups with respect to the overall infection rate. However, studies by Skaggs, Sungaram, Harley and Al-Arabi have emphasized the importance of prophylactic antibiotics [6, 20-22]. Early administration of antibiotics is now considered a standard of care [1-3, 7, 18]. A recent Cochrane systematic review showed that the administration of antibiotics after an open fracture reduces the risk of infection by $59 \%$ [26]. Our results show that there is no increased risk of infection if 
Table 3 Various fixation techniques

\begin{tabular}{lrrr}
\hline Treatment & III A & III B & III C \\
\hline External fixator & 11 & 20 & 2 \\
Intra-medullary Nailing & 9 & 12 & \\
Plating & 4 & 4 & \\
Others (Steinman pin, POP) & 2 & 3 & \\
Total & 26 & 39 & 2 \\
\hline
\end{tabular}

first debridement is delayed beyond the 6-h threshold. All the patients in our study received prophylactic antibiotics in emergency department as a part of primary management.

The average rate of infection in grade III fractures is $10-50 \%$ depending on the severity of the injury $[1,7,10$, $27,28]$. The overall infection rate in this study was $14.9 \%$ (10 cases), decreasing to $12 \%$ if the two cases of pin tract infection were excluded. All these patients had Gustilo III $\mathrm{B}$ injuries. There were two cases of grade III $\mathrm{C}$ fracture, which were operated within $6 \mathrm{~h}$ of presentation; both underwent urgent debridement, external fixation and posterior tibial artery reconstruction (Table 3).

Debridement in grade III open fractures needs to be performed by an experienced surgeon. Naique et al. [29] reported an association between adequacy of debridement and infection and suggested that adequacy of the debridement, rather than timing, determines outcome.

Our study suggests that there is no association between time to debridement and infection rate. It may be prudent to delay definitive debridement so that better treatment by experienced surgeons and staff familiar with equipment can be provided. In a busy District General or peripheral hospital, where immediate access to theatre for all such injuries may not be possible, delaying debridement for some injuries may not influence the outcome. The limitation of our study is that it is a retrospective case-control study. A power analysis by Skaggs et al. [23] revealed that 11,390 cases would be needed in order to detect a $20 \%$ difference in infection rate.

Skeletal stabilization should be performed at the time of initial debridement $[3,30,31]$. This can be achieved by intramedullary nails, plates or external fixators depending on the morphology of the fracture. Restoring alignment of the limb eliminates gross movement at the site of fracture, limits further soft tissue damage and decreases the risk of further bacterial spread [30,31]. Nearly half of the patients $(46 \%)$ in our study were treated with an external fixator and $30 \%$ by an intramedullary nail.

We suggest the 6-h rule must be interpreted with caution. In a level 1 trauma centre, it may be possible to gain prompt theatre access to allow this rule to be satisfied. However, this and other studies have indicated that the infection rate is not associated with a reasonable delay to debridement, especially if the delay is to facilitate treatment by the appropriate senior surgical personnel. Our study also recognizes the importance of a multi-disciplinary management protocol as recommended by the recent BOA/BAPRAS (British Orthopaedic Association/ British Association of Plastic, Reconstructive and Aesthetic surgeons) standards for management of open fractures [18].

\section{Conclusion}

This study suggests that infection rate is not increased if the primary surgical debridement was delayed more than $6 \mathrm{~h}$ after injury. Reasonable delays in surgical treatment for patients with open fractures may be justified in order to provide an optimal operating environment.

\section{Conflict of interest None.}

Open Access This article is distributed under the terms of the Creative Commons Attribution License which permits any use, distribution, and reproduction in any medium, provided the original author(s) and the source are credited.

\section{References}

1. Okike K, Bhattacharyya T (2006) Trends in the management of open fractures. A critical analysis. J Bone Joint Surg Am 88:2739-2748

2. Zalavras CG, Marcus RE, Levin LS et al (2008) Management of open fractures and subsequent complications. Instr Course Lect 57:51-63

3. Giannoudis PV, Papakostidis C, Roberts C (2006) A review of the management of open fractures of the tibia and femur. J Bone Joint Surg Br 88:281-289

4. Cole JD, Ansel LJ, Schwartzberg R (1995) A sequential protocol for management of severe open tibial fractures. Clin Orthop Relat Res 315:84-103

5. Webb LX, Bosse MJ, Castillo RC et al (2007) Analysis of surgeon-controlled variables in the treatment of limb-threatening type-III open tibial diaphyseal fractures. J Bone Joint Surg Am 89:923-928

6. Al-Arabi YB, Nader M, Hamidian-Jahromi AR et al (2007) The effect of the timing of antibiotics and surgical treatment on infection rates in open long-bone fractures: a 9-year prospective study from a district general hospital. Injury 38:900-905

7. Zalavras CG, Marcus RE, Levin LS et al (2007) Management of open fractures and subsequent complications. J Bone Joint Surg Am 89:884-895

8. Gregory P, Sanders R (1995) The management of severe fractures of the lower extremities. Clin Orthop Relat Res 318:95-105

9. Patzakis MJ, Wilkins J, Moore TM (1983) Considerations in reducing the infection rate in open tibial fractures. Clin Orthop Relat Res 178:36-41

10. Gustilo RB, Anderson JT (1976) Prevention of infection in the treatment of one thousand and twenty-five open fractures of long 
bones: retrospective and prospective analyses. J Bone Joint Surg Am 58:453-458

11. Cierny G III, Byrd HS, Jones RE (1983) Primary versus delayed soft tissue coverage for severe open tibial fractures. A comparison of results. Clin Orthop Relat Res178:54-63

12. Spencer J, Smith A, Woods D (2004) The effect of time delay on infection in open long-bone fractures: a 5-year prospective audit from a district general hospital. Ann R Coll Surg Engl 86:108-112

13. Charalambous CP, Siddique I, Zenios M et al (2005) Early versus delayed surgical treatment of open tibial fractures: effect on the rates of infection and need of secondary surgical procedures to promote bone union. Injury 36:656-661

14. Kindsfater K, Jonassen EA (1995) Osteomyelitis in grade II and III open tibia fractures with late debridement. J Orthop Trauma 9:121-127

15. Friedrich $P$ (1898) Die Aseptische Versorgung frischer Wundern. Arch Klin Chir 57:288-310

16. Robson MC, Duke WF, Krizek TJ (1973) Rapid bacterial screening in the treatment of civilian wounds. J Surg Res $14: 426-430$

17. Gustilo RB, Mendoza RM, Williams DN (1984) Problems in the management of type III (severe) open fractures: a new classification of type III open fractures. J Trauma 24:742-746

18. BOA (2009) Standards for the management of open fractures of the lower limb. BAPRAS 1-24. http://www.boa.ac.uk/site/ showpublications.aspx?id=59

19. Robson MC (1997) Wound infection. A failure of wound healing caused by an imbalance of bacteria. Surg Clin North Am 77:637-650

20. Kreder HJ, Armstrong P (1995) A review of open tibia fractures in children. J Pediatr Orthop 15:482-488

21. Pollak AN, Jones AL, Castillo RC et al (2010) The relationship between time to surgical debridement and incidence of infection after open high-energy lower extremity trauma. J Bone Joint Surg Am 92:7-15

22. Sungaran J, Harris I, Mourad M (2007) The effect of time to theatre on infection rate for open tibia fractures. ANZ J Surg 77:886-888

23. Skaggs DL, Friend L, Alman B et al (2005) The effect of surgical delay on acute infection following 554 open fractures in children. J Bone Joint Surg Am 87:8-12

24. Harley BJ, Beaupre LA, Jones CA et al (2002) The effect of time to definitive treatment on the rate of nonunion and infection in open fractures. J Orthop Trauma 16:484-490

25. Bednar DA, Parikh J (1993) Effect of time delay from injury to primary management on the incidence of deep infection after open fractures of the lower extremities caused by blunt trauma in adults. J Orthop Trauma 7:532-535

26. Gosselin RA, Roberts I, Gillespie WJ (2004) Antibiotics for preventing infection in open limb fractures. Cochrane Database Syst Rev 1:CD003764

27. Patzakis MJ, Wilkins J (1989) Factors influencing infection rate in open fracture wounds. Clin Orthop Relat Res 243:36-40

28. Gustilo RB, Gruninger RP, Davis T (1987) Classification of type III (severe) open fractures relative to treatment and results. Orthopedics 10:1781-1788

29. Naique SB, Pearse M, Nanchahal J (2006) Management of severe open tibial fractures: the need for combined orthopaedic and plastic surgical treatment in specialist centres. J Bone Joint Surg $\mathrm{Br} 88: 351-357$

30. Worlock P, Slack R, Harvey L et al (1994) The prevention of infection in open fractures: an experimental study of the effect of fracture stability. Injury 25:31-38

31. Pallister I, Empson K (2005) The effects of surgical fracture fixation on the systemic inflammatory response to major trauma. J Am Acad Orthop Surg 13:93-100 